\title{
Ischnura praematura sp. nov. (Odonata: Zygoptera: Coenagrionidae): a species from Yunnan (China) whose females mate in the teneral state
}

\author{
IAGO SANMARTÍN-VILLAR ${ }^{1 *}$, M. OLALLA LORENZO-CARBALLA ${ }^{1,3}$, \\ HAOMIAO ZHANG ${ }^{2}$ \& ADOLFO CORDERO-RIVERA ${ }^{1,4}$ \\ ${ }^{1}$ Universidade de Vigo, ECOEVO Lab, Escola de Enxeñaría Forestal, Campus A Xunqueira 36005 Pontevedra, Galiza, Spain \\ ${ }^{2}$ Kunming Natural History Museum of Zoology, Kunming Institute of Zoology, Chinese Academy of Sciences, Kunming, Yunnan 650223, \\ China \\ ${ }^{3} \odot$ https://orcid.org/0000-0003-4570-2594 \\ 4 ○ https://orcid.org/0000-0002-5087-3550 \\ *Corresponding author. "sv.iago@gmail.com; @ https://orcid.org/0000-0002-5008-7613
}

\begin{abstract}
Ischnura praematura sp. nov. (Holotype đ̄, China, Yunnan, Lijiang, 26³1'03.54'N, 100¹3'38.89'E, 2396 m, 04 xii 2015, I. Sanmartín-Villar \& H. Zhang leg.) is morphologically described, illustrated and compared with close species of the genus. Ischnura praematura can be mainly distinguished from its congeners I. aurora, I. rubilio and I. asiatica by its abdominal and thoracic morphology and colouration. The posterior lobe of the prothorax is elevated in I. praematura and the mesostigmal plates possess dorsal triangular protuberances. Ischnura praematura shows pointed paraprocts, internalised wide cerci and lacks a dorsal tuberculum in the tenth abdominal segment. The blue abdominal colouration is present in the last three segments (incomplete for segment eight and ten in some individuals). No female polychromatism was detected and all females observed possessed different colouration than male (gynochrome). Morphological distinctiveness of the species is supported by genetic analyses, which show that I. praematura forms a well-supported, monophyletic clade, with I. asiatica, I. ezoin and I. pumilio as the most closely related species. In the field, mature females show strong reluctance to mate, and males were observed mating with newly emerged females.
\end{abstract}

Key words: Asia, damselfly, integrative taxonomy, molecular markers, mitochondrial DNA, nuclear DNA

\section{Introduction}

The genus Ischnura (Chapentier, 1840) (Odonata: Coenagrionidae) is represented by a large number of species distributed across the world (a total of 76 species currently described; Sánchez-Guillén et al. 2020). Some of these are species able to live in a range of environments, including ponds, lakes, saltmarshes and rivers, and spreading themselves across large distribution areas (for instance, I. elegans (Vander Linden, 1820) and I. senegalensis (Rambur, 1842) are found throughout Europe, as far as to Japan, and even parts of Africa for senegalensis; SánchezGuillén et al. 2020), while others are restricted to relatively small areas (e.g. I. genei, a species found only in some Mediterranean islands; Dijkstra \& Lewington 2006).

At the intraspecific level, Ischnura is also highly diverse, due to the presence of age-related colour phases and, in many species, female polychromatism (see Sánchez-Guillén et al. 2020). Body colouration varies in Ischnura between phenotypes, development stages, seasons, populations, and/or laboratory rearing conditions (Cordero-Rivera 1987; Sanmartín-Villar et al. 2016; Sanmartín-Villar \& Cordero-Rivera 2016). Behavioural diversity (see CorderoRivera 2017) is also characteristic of this genus, which possess inter- and intraspecific differences in lifespan (e.g. Debecker et al. 2016) and reproductive strategies (e.g. Lorenzo-Carballa et al. 2012). Mate recognition (e.g. Miller \& Fincke 1999) followed by morphological compatibility (Cordero-Rivera \& Córdoba-Aguilar 2010) constitutes the first step responsible of species divergence and hybridization (e.g. Sánchez-Guillén et al. 2005, 2020), and may thus be an important trigger of evolutionary processes.

Disentangling hidden variability within communities constitutes also a key factor in ecological studies and 
conservation programs. However, the high degree of morphological and colour variability shown by many Ischnura species may hamper their taxonomical identification, especially in less studied geographical areas, where species with similar morphology or colour may coexist. For instance, the status of the populations of I. rufostigma (Selys, 1876), a species with a rather confusing colouration variability occurring in the province of Yunnan (China), was recently clarified (Sanmartín-Villar et al. 2016).

Here, we combine morphological analyses with sequencing of mitochondrial and nuclear DNA, to describe and illustrate a new species from the same Chinese province of Yunnan: I. praematura sp. nov., which had remained unnamed and without a formal description since its discovering (see Zhang 2019). The morphology and colouration of this species are compared to that of I. aurora (Brauer, 1865), I. rubilio (Sleys, 1876) and I. asiatica (Brauer, 1865), which show similar morphological traits. Finally, we describe its particular reproductive behaviour, consisting in mature males harassing and mating newly emerged (teneral) females as it has been described for I. aurora in the Pacific islands (Rowe 1978, 2010).

\section{Material and methods}

\section{Sample collection and morphological examination}

Samples analysed in this work were collected on $4^{\text {th }}$ July 2015 close to Lijiang city (Table 1; Figure 1). Adult individuals were captured using a hand net and preserved in $80 \%$ ethanol at $4{ }^{\circ} \mathrm{C}$. Population density was estimated by collecting all individuals observed in 10 minutes. We noted tandem and mating events observed between 09:30 $\mathrm{h}$ and $12: 30 \mathrm{~h}$.

Additionally, we examined 10 males (ACR-2338, ACR-2379, ACR-2880, ACR-3504 from China; ACR-0738, ACR-0818, ACR-0819 from Australia; and, ACR-5007, ACR-5009, ACR-5010 from Fiji) and 6 females (ACR3508, ACR-3511 from China and ACR-0776, ACR-0793, ACR-0794, ACR-0795 from Australia) of I. aurora; and one male (ACR-3571) and one female (ACR-3578) of I. asiatica from A. Cordero-Rivera's personal collection. Also, we examined three males and one female of I. rubilio from India, belonging to M. Bedjanič's personal collection. We also had access to images from I. rubilio specimens belonging to the collections of R. Babu, K. A. Subramanian, and H. Dumont.

Photographs in the field were taken using a Canon EOS 60D. Body parts were photographed using a Leica Flexacam C1 camera attached to an Olympus SZ60 stereoscopic microscope. The male ligula from two specimens (ACR-3520, ACR-3523) was dissected and photographed under a scanning electron microscope (Philips XL30). Terminology used in the morphological description follows that in Garrison et al. (2010).

\section{DNA extraction, sequencing and genetic analyses}

Four specimens of Ischnura sp. collected nearby Lijiang (Yunnan, China; Figure 1), along with representatives of $I$. aurora from China, Australia and Fiji, all of them belonging to Adolfo Cordero-Rivera's personal collection, were selected for genetic analyses (see Table 1). Total genomic DNA was extracted from a single leg of each individual using the GeneJet DNA extraction kit (ThermoFisher Scientific, Waltham, MA, USA), following the manufacturer's protocol. We amplified fragments of the mitochondrial Cytochrome Oxidase I (COI) gene, and the nuclear Internal Transcribed Spacer(ITS), using previously published primer pairs(COI-S0: TACCAATTATAATTGGAGGATTYGG / COI-AS0: CTTCTGGATGTCCAAARAATCA and ITS-F0: GGAAAGATGGCCAAACTTGA / ITS-28SAS0: CCTCCGCTTATTAATATGCTTAAATTC; Futahashi et al. 2018). PCR reactions were carried out at specific annealing temperatures $\left(48^{\circ} \mathrm{C}\right.$ for COI and $52{ }^{\circ} \mathrm{C}$ for ITS) using the DreamTaq Green PCR Master Mix (ThermoFisher Scientific). Prior to sequencing, unincorporated primers and dNTPs were removed using Shrimp Alkaline Phosphatase and Exonuclease I (New England Biolabs, Ipswich, MA, USA). Cleaned PCR products were sequenced in both directions using BigDye v.3.1 chemistry (Applied Biosystems, Foster City, CA, USA) in an ABI 3730xl DNA Analyzer (Applied Biosystems), at the Macrogen Spain facilities in Madrid.

After sequencing, chromatograms were visually inspected, trimmed and assembled using Geneious v. 9.1.7 (https://www.geneious.com). BLAST searches were run through Geneious v. 9.1.7 for all DNA sequences, to ensure that they were not derived from contaminations. Sequences generated in this study have been deposited in the GenBank sequence database (https://www.ncbi.nlm.nih.gov/genbank/), under accession numbers MZ514804MZ514821 (see Table 1). 


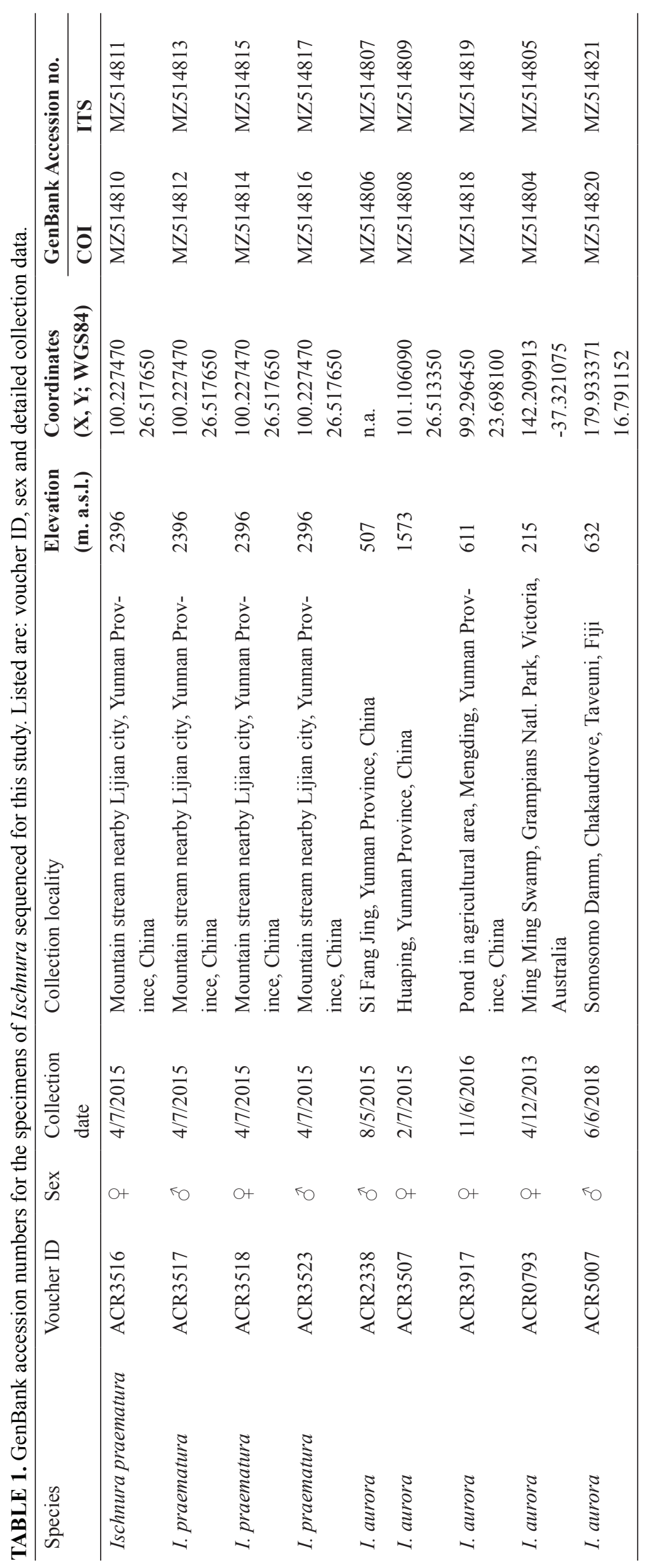




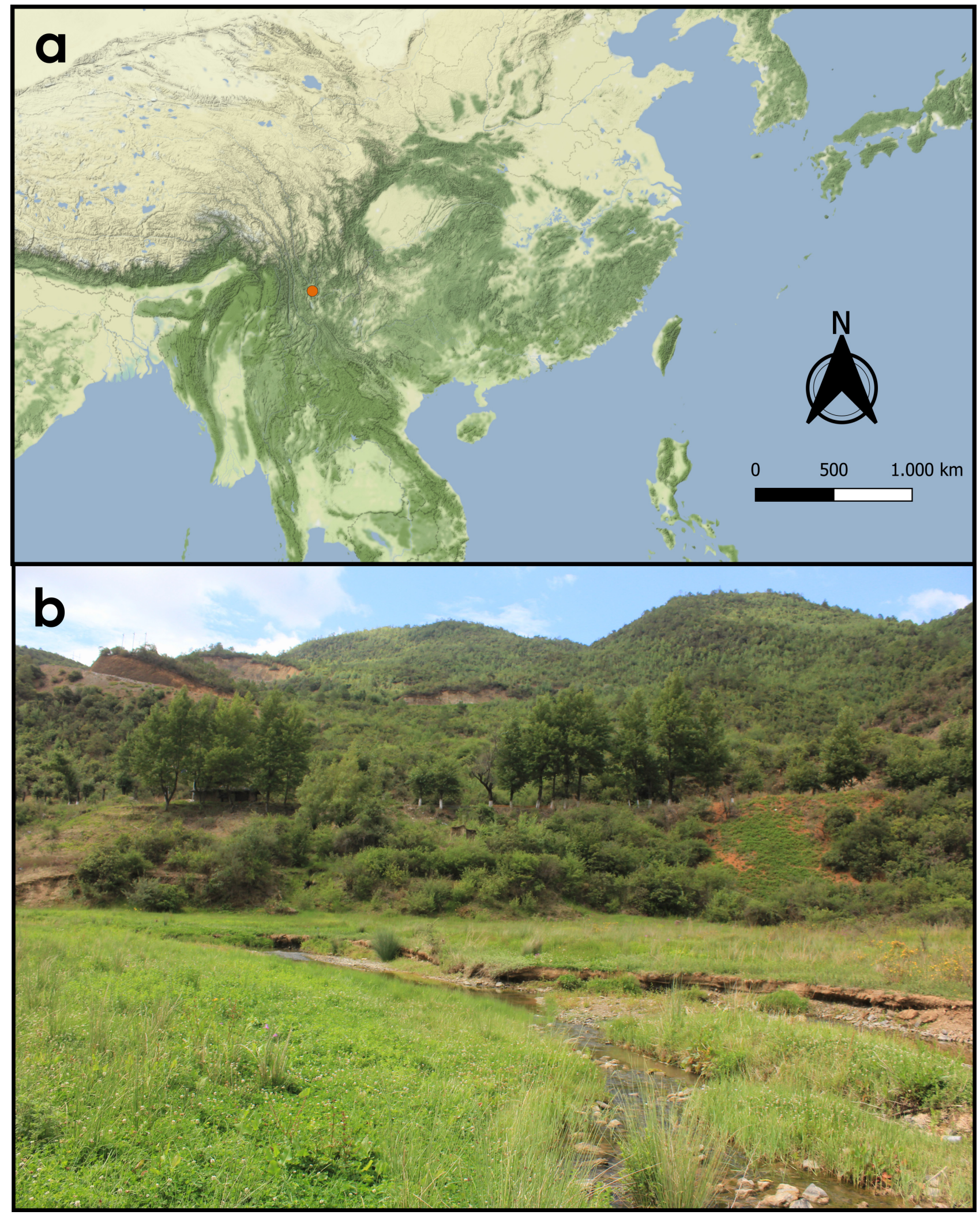

FIGURE 1. a: Type locality of Ischnura praematura, nearby Lijiang city (Yunnan Province, China). b: Habitat where the species was found. Photo by I. Sanmartín-Villar.

Previously published sequences from several Ischnura species were downloaded from GenBank, and added to our datasets. Sequences of Enallagma cyathigerum and E. circulatum were also downloaded and used as outgroups in the phylogenetic analyses (see Figure 9). 
Sequences were aligned using MAFFT (Katoh et al. 2002; Katoh \& Standley 2013) as implemented in Geneious v. 9.1.7. Alignments were exported into MEGA X (Kumar et al. 2018) for estimation of genetic differentiation between species. Genetic p-distances were estimated with the pairwise deletion option, which removes all ambiguous positions for each sequence pair. Phylogenetic relationships among Ischnura species were reconstructed using maximum likelihood (ML) and Bayesian inference (BI) approaches. ML analyses were carried out using RAxML 7.2.8. (Stamatakis 2014) as implemented in Geneious v. 9.1.7, using the rapid bootstrapping and search for best scoring ML tree option, under the GTR $+\mathrm{G}+\mathrm{I}$ model. Support for the nodes in the resulting tree was estimated by running 1,000 bootstrap replicates. BI analyses were conducted using MrBayes 3.2.6 (Huelsenbeck \& Ronquist 2001; Ronquist \& Huelsenbeck 2003) also implemented in Geneious v. 9.1.7. Searches were run for 1.1 million generations, with default priors and the GTR $+\mathrm{G}+\mathrm{I}$ substitution model.

\section{Ischnura praematura sp. nov. Sanmartín-Villar \& Zhang}

Figures 2-4

Holotype. $\widehat{\gamma}$ (currently at ECOEVO Lab, to be deposited at Kunming Natural History Museum of Zoology, ACR3521), China, Yunnan, Lijiang, 26 31'03.54”N, 100¹3’38.89”E, 2396 m, 04.vii.2015, I. Sanmartín-Villar \& H. Zhang leg.; Figure 2a).
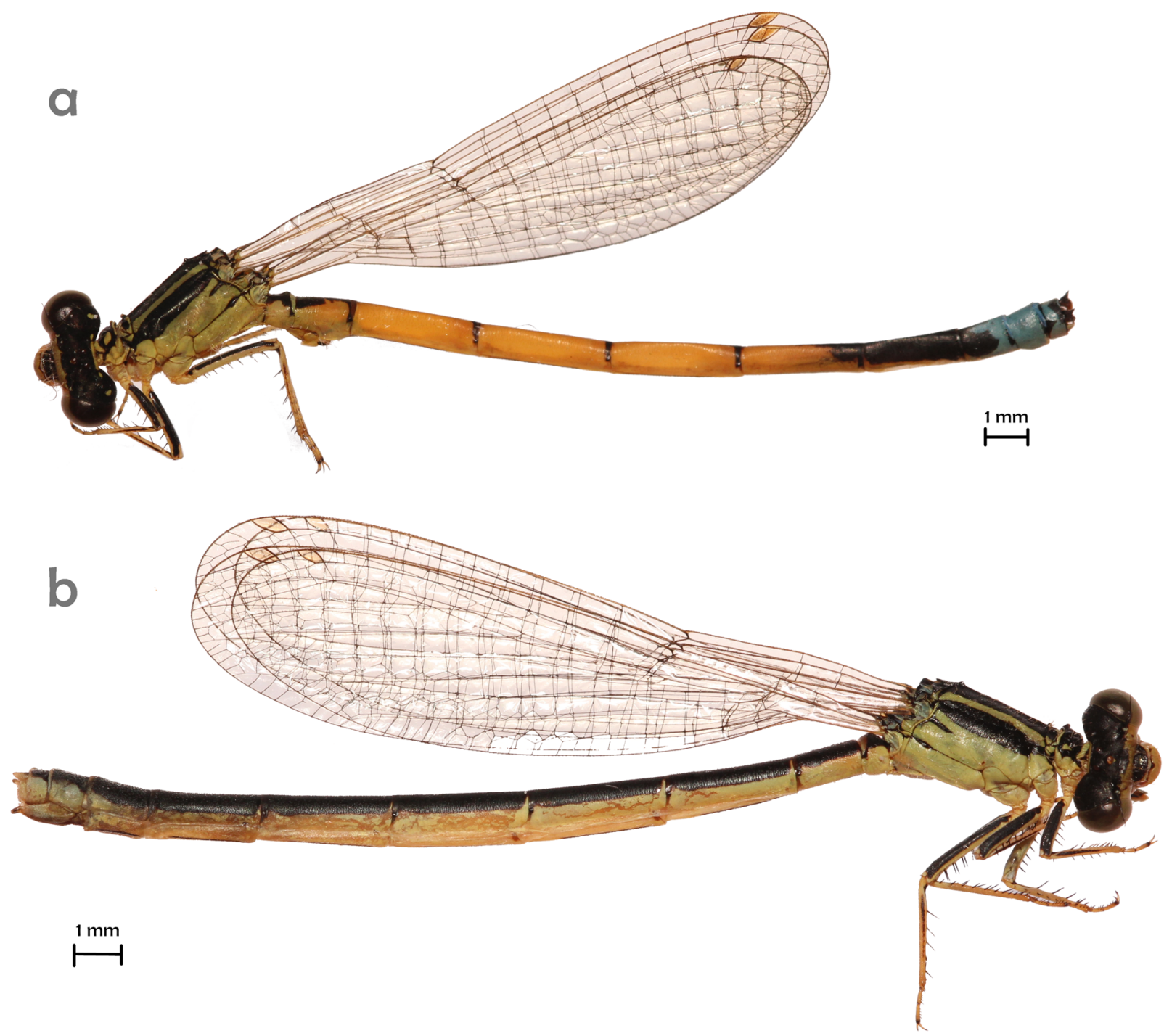

FIGURE 2. Ischnura praematura sp. nov., holotype $\hat{\jmath}$ (a) and $q$ allotype (b). 
Paratypes. $4 \widehat{\partial} \widehat{\partial}$ (ECOEVO Lab, ACR-3517, ACR-3520, ACR-3522, ACR-3523) and 4 q $q$ (ECOEVO Lab, ACR-3515, ACR-3516, ACR-3518, ACR-3519). Same collection data as the holotype. $1 \delta^{\lambda}$ and 19 (Xiaohexiang village, Kunming city, Yunnan province, 04. Vi. 2021, Haomiao Zhang leg; 15.vi.2014, Sanjiacun, Dali city, Yunnan province, Haomiao Zhang leg).

Allotype. + (ECOEVO Lab, ACR-3514; Figure 2b). Same collection data as the holotype.

Etymology. Specific name praematura (i.e. premature: occurring before a state of readiness or maturity has arrived) in reference to its reproductive behaviour, in which mature males mate with newly emerged females before they reach sexual maturity (see below).

\section{Description of holotype}

Head (Figure 3a-b). Mainly yellow-green except for some black colouration present on the upper border of the labrum (arrow-like mark), the postclypeus and the upper part of the epicranium. Antennae completely black, except for the yellow-green basal segment. Postocular spots, which are small and rounded, and occipital bar (a central line with one spot at each side) also yellow-green.
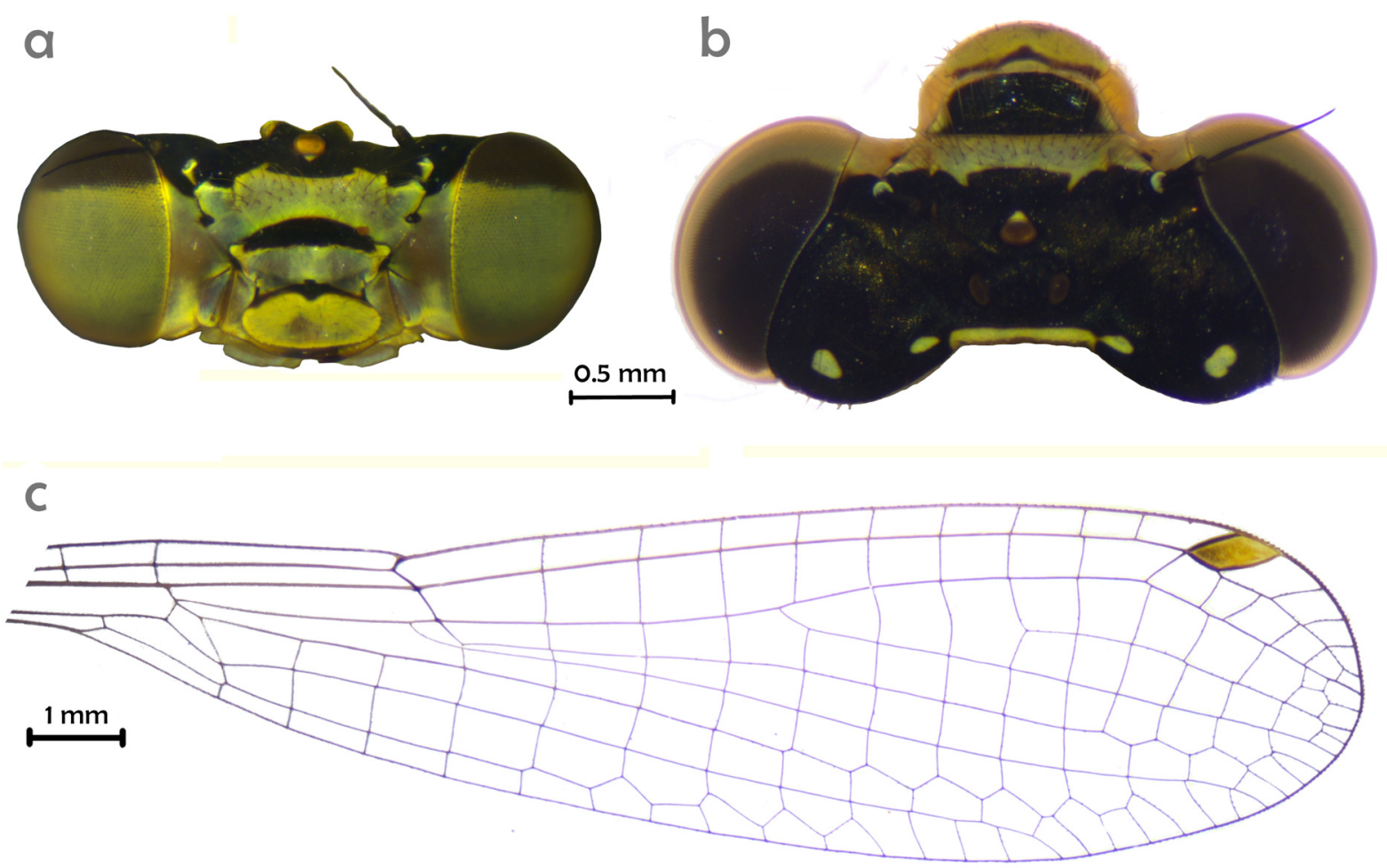

FIGURE 3. Ischnura praematura male head (a: frontal view; b: dorsal view) and hindwing (c).

Thorax (Figure 2a). Dorsal part of the pronotum's middle lobe black with one yellow-green spot at each side. Propleuron yellow-green. The posterior lobe of the pronotum shows an elevated central notch, like a saddle cantle. The mesostigmal plate possesses four dorso-lateral triangular protuberances pointing to the sides (Figures 6a, 8a). The dorsal pair of these protuberances are dorsally projected and possess a hook-shaped apical expansion that points laterally, outwards from the body. The lateral protuberances are triangular in shape, and point also laterally outwards from the body. Thorax is mainly yellow-green, except for the blackish middorsal carina, a broader line covering the humeral suture expanded towards the mesepisternum (first segment) and mesepimeron (second segment), a spot at the posterior region of the interpleural suture, and a narrow lateral suture enlarged at the posterior region in the junction between the metepisternum and metepimeron.

Legs (Figure 2a). All parts yellow-green except dorsally black in femur, tibia and the tip of the third tarsal segment. Black colour narrows in the distal part of femur and is not present in the distal part of the tibia.

Wings (Figures 2a, 3c). Hyaline. Nine postnodal veins. Pterostigma bicolour, blurring between blackish (anterior) towards light brown (posterior). Colours more differentiated in hindwings than forewings. 

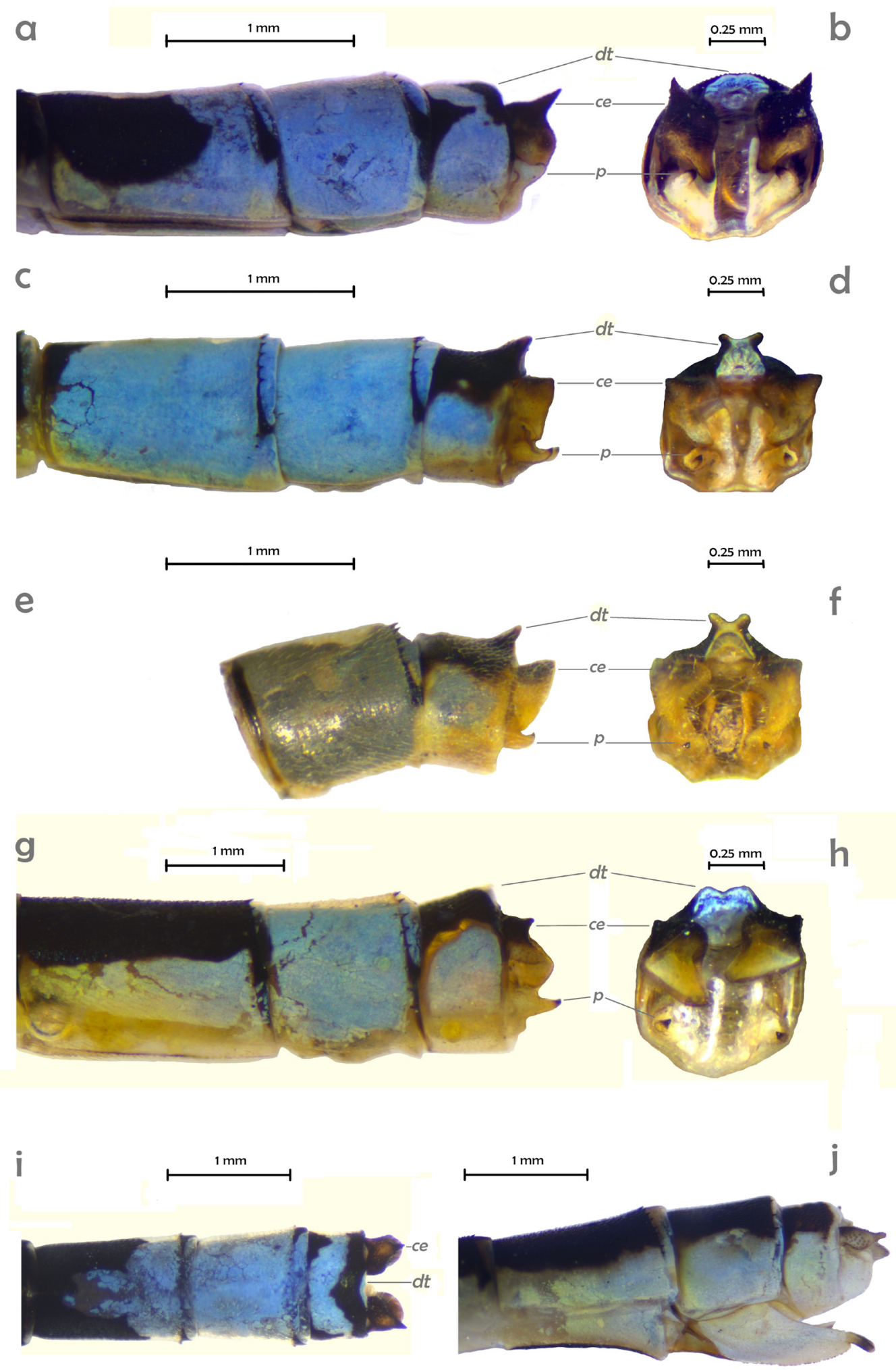

FIGURE 4. Ischnura praematura morphological details and comparison with I. aurora collected in China (c-d), I. rubilio collected in India (e-f), and I. asiatica collected in China ( $\mathbf{g}-\mathbf{h})$. a: lateral view of the last abdominal segments of I. praematura $(\precsim)$; b: posterior view of the anal appendages of I. praematura $(\delta)$; $\mathbf{c}$ : lateral view of the last abdominal segments of $I$. aurora $(\lesssim)$; d: posterior view of the anal appendages of I. aurora (ठ); e: lateral view of the last abdominal segments of I. rubilio (đ); f: posterior view of the anal appendages of I. rubilio (ठ); g: lateral view of the last abdominal segments of $I$. asiatica (ठ); h:

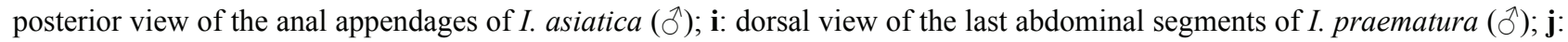
lateral view of the last abdominal segments of I. praematura $(+)$. $d t$, dorsal tubercle; $c e$, cerci; $p$, paraprocts. 
Abdomen (Figure 2a). S1 and S2 black dorsally, greenish and yellow-reddish in the lateral and ventral region respectively. S3 to S5 completely yellow-reddish except for black intersegment areas. S6 mostly yellow-reddish, and black in the 1/5 posterior part. S7 dorsally black and ventrally green-yellow (Figure 2a). S8 with blue colour describing a lower case omega ( $\omega$, considering lateral plus dorsal view; Figures $4 a$, i). S9 blue. S10 blue, with a basal black delta-shaped mark and two triangular anterior black marks. Protuberance in S10 not elevated and dorsally blue.

Genital ligula (Figure 5). Close to the junction with the second segment, the first ligula segment presents a triangular spot of short spines at the basis and a group of long spines at the middle. Second segment with a pair of curved long spines and a pair of C-shape long and wide flagella. The ventral region of the flagella is covered by short spines aligned in rows.
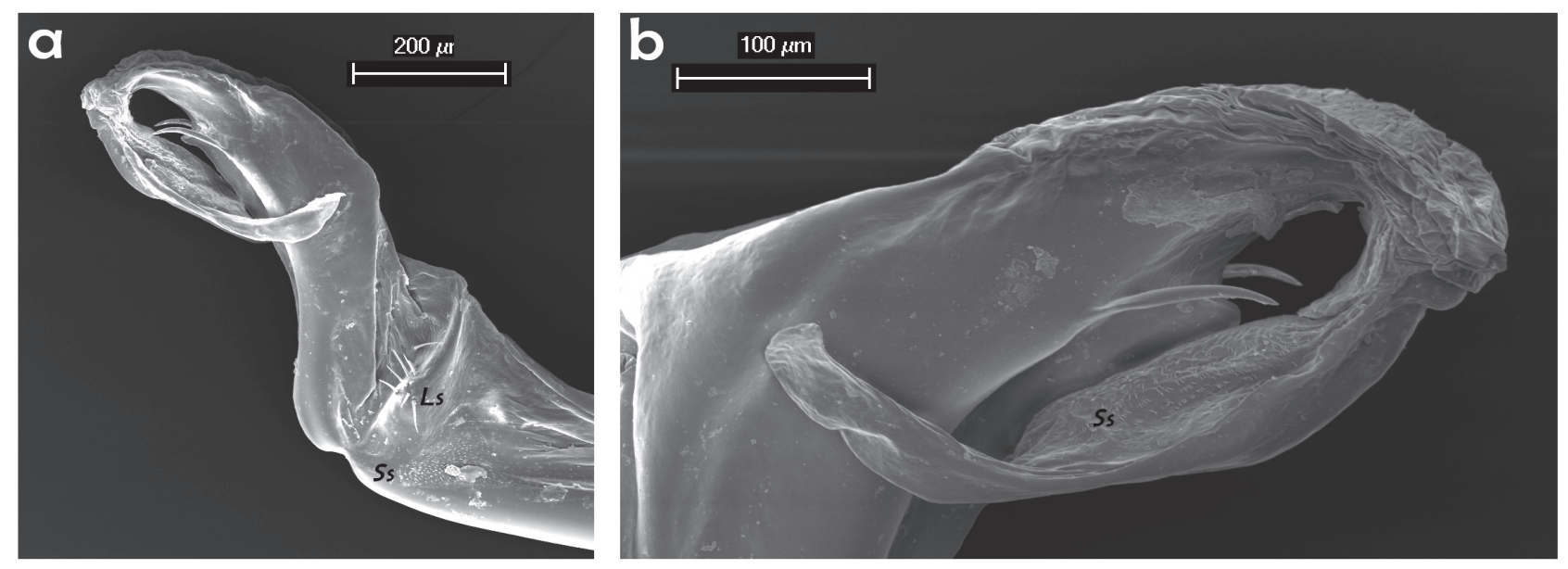

FIGURE 5. Lateral view of the male genital ligula of I. praematura (a: 100x; b: 250x). Ss: short spines; Ls: long spines.

Anal appendages (Figures 4a, b, i). In lateral view (Figure 4a), the dorsal part of the cerci is darker and elongated forming an upwards directed spine. Paraprocts are small and do not extend beyond the cerci. In posterior view (Figure $4 b$ ), the spines of the cerci are divergent, whereas the tip of the paraprocts are convergent.

Body length $=24.9 \mathrm{~mm}$; abdominal length $=19.0 \mathrm{~mm}$; hindwing length $=13.8 \mathrm{~mm}$.

Description of allotype. Similar colour patterns and shape as males in head, legs and wings, but turquoise green instead yellow-green (Figure 2b).

The posterior lobe of the pronotum shows a discontinuous notch, only present in the lateral regions (Figures $6 \mathrm{~b}$, $7 b)$. Mesostigmal plates do not show developed dorsal protuberances as in males (Figure $8 b$ ).

Abdomen (Figures $2 b, 4 j$ ). Dorsally black and ventrally green. Without vulvar spine. Genital valves overpass the base of the cerci but the stylus does not reach the tip of the cerci. Cerci longer than S10 and are narrow at the tip.

Body length $=25.4 \mathrm{~mm}$; abdominal length $=19.2 \mathrm{~mm}$; hindwing length $=14.9 \mathrm{~mm}$.

Variations in paratypes. There is slight variation in the number of wing veins (up to two additional veins in all wing rows). The blue colouration of male S10 is laterally interrupted by black spots in some specimens, so that they show a blue dorsal dot and a pair of blue lateral regions. No polychromatism was observed and all females showed a greenish colouration pattern different than males (gynochrome). Older individuals develop a grey wax over the cuticle (pruinescence; Figure 10B).

Differential diagnosis. Similar at naked eye in size and colouration to I. aurora and I. rubilio, I. praematura can be distinguished from these two species by the first thoracic segments in males and females and by the anal appendages and the abdominal colouration in males. The elevated central notch that appears in the posterior lobe of the pronotum of I. praematura (Figure 6a, 8a), is not found in I. aurora (Figure 6c, 8c) and I. rubilio (Figures 6e, 8e). The middle part of the posterior lobe is not expanded in I. praematura (males: Figures 6a, 7a; females: Figures 6b, $7 \mathrm{~b}$ ) as it occurs in the other two species (I. aurora males: Figures 6c, 7c; females: Figures 6d, 7d; I. rubilio males: Figures $6 \mathrm{e}, 7 \mathrm{e}$; females: Figures $6 \mathrm{f}, 7 \mathrm{f})$. The dorsal protuberances on the mesostigmal plates are triangular with apical expansion in I. praematura (Figures 6a, 8a), while in I. aurora (Figures 6c, 8c) and I. rubilio (Figures 6e, 7e) these are rounded and their basis are narrower. Female mesostigmal plates are wider in I. praematura (Figure 8b) 

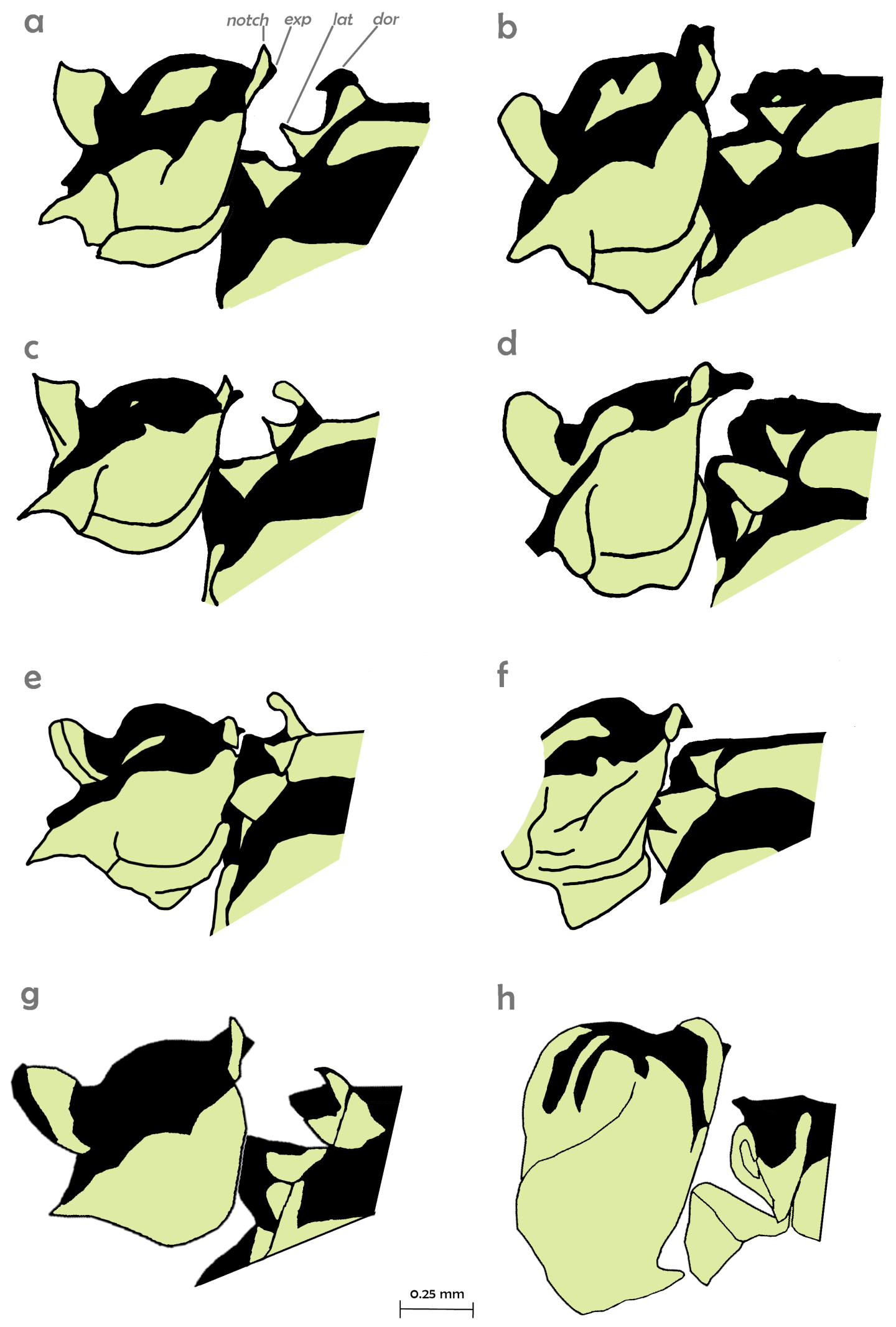

h

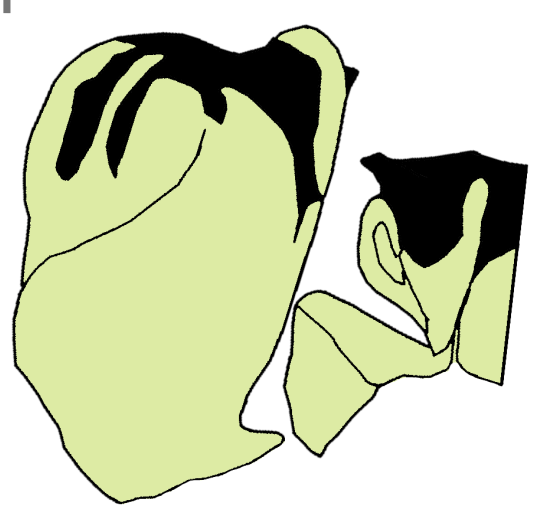

FIGURE 6. Scheme of the pronotum and mesostigmal plates in lateral view of Ischnura praematura ( $\hat{\delta} \mathbf{a} ; \uparrow \mathbf{b})$, I. aurora from China ( $\hat{\sigma} \mathbf{c} ; q \mathbf{d}), I$. rubilio from India $(\hat{\sigma} \mathbf{e} ; q \mathrm{f}$,$) , and I$. asiatica from China $(\hat{\sigma} \mathrm{g} ; q \mathrm{~h})$. notch: pronotum posterior lobe notch, exp: pronotum posterior lobe expansion, lat: mesostigmal plate lateral protuberance, dor: mesostigmal plate dorsal protuberance. 
than in the other cited species (Figures 8d, f). All observed male specimens of I. praematura possess no elevated dorsal tubercule in the abdominal S10 (Figures 4a, b), while this structure is highly prominent in I. aurora (Figures 4c, d) and I. rubilio (Figures 4e, f). The superior part of the I. praematura cerci is expanded in a long spine differentiated from the basis (Figures 4a, b), in opposition to the continuous shape in I. aurora (Figures 4c, d) and I. rubilio (Figures 4 e, f). Paraprocts are separated from cerci in I. aurora (Figure 4c) and I. rubilio (Figure 4e), while in I. praematura the paraprocts are wider and they appear, in a lateral view, masked by the cerci (Figure 4a). Ischnura praematura is the only of these three species that shows blue colouration on the dorsal part of the abdominal S10 (Figure 4i).

At naked eye, I. asiatica differs from I. praematura in its abdominal colouration (black and green-yellow with only S9 dorsally blue) and larger body size (body length $=27.5 \mathrm{~mm}$; hindwing $=14.2 \mathrm{~mm}$ ). However, males of I. praematura and I. asiatica are similar in the first thoracic segments and in the anal appendages, and clearly different from I. aurora or I. rubilio. Ischnura asiatica also possess an elevated central notch in the posterior lobe of the pronotum (Figure 6g), although it is not interrupted in the middle (Figure 7g; also in females; Figure 7h) as in I. praematura (male: Figure 7a; female: Figure 7b). The middle part of the posterior lobe is not expanded as in I. praematura (Figure $6 \mathrm{~g}, 7 \mathrm{~g}$ ), but I. asiatica shows two triangular lateral expansions (Figure $7 \mathrm{~g}$; also present in females; Figure 7h) not found in I. praematura. The dorsal protuberances on the mesostigmal plates are triangular with apical expansion in I. praematura and I. asiatica, but they are wider in the former. Female mesostigmal plates are narrower in I. asiatica (Figure 8h). The dorsal tubercle is more elevated in I. asiatica than in I. praematura, and is dorsally blue in both species. The superior part of the $I$. asiatica cerci is expanded but not developing a long spine as in I. praematura. Paraprocts are narrow and laterally separated from cerci in I. asiatica in contrast with $I$. praematura. Blue colouration is restricted to the dorsal tubercle in I. asiatica S10.
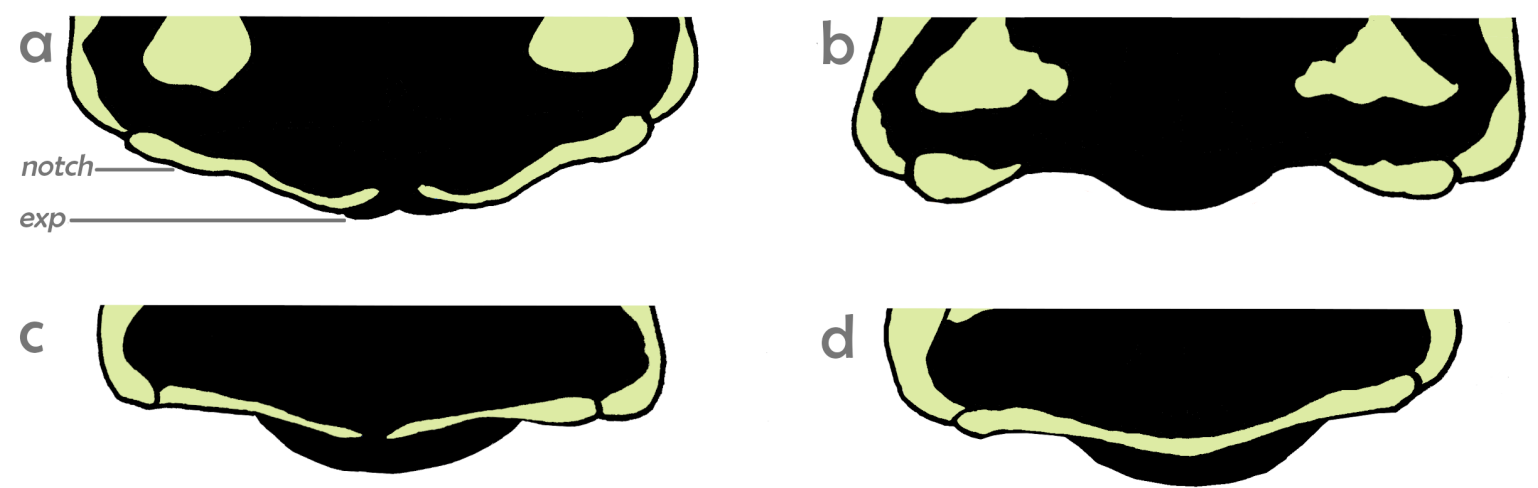

e

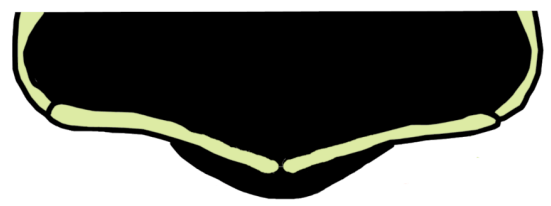

f

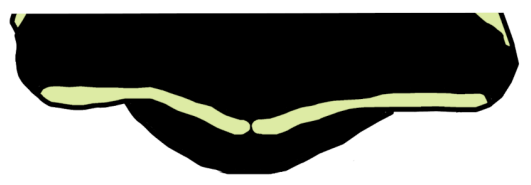

g

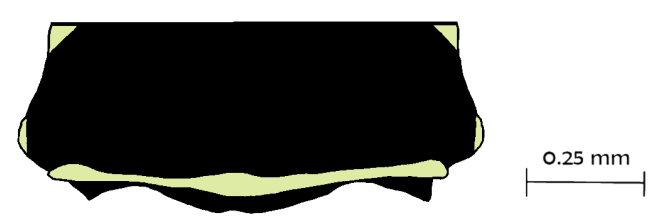

h

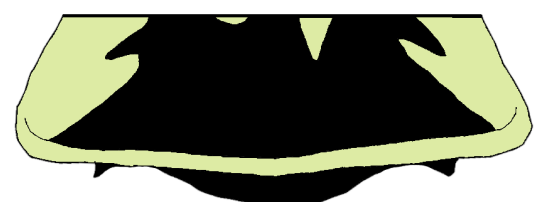

FIGURE 7. Scheme of the pronotum in dorsal view of Ischnura praematura ( $\delta \mathbf{a} ; \not \mathbf{b})$, I. aurora from China $(\hat{\sigma} \mathbf{c} ; \not \mathbf{d}), I$.

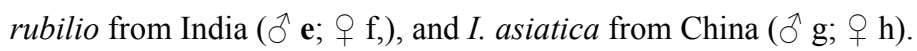

Phylogenetic relationships with other Ischnura species. Obtained sequences were all identified by BLAST as similar to other odonate species in the NCBI databases. Results of phylogenetic analyses were congruent for both mitochondrial and nuclear datasets, and also for BI and ML analyses. All the Ischnura specimens collected at Lijiang formed a monophyletic and well supported clade (Figure 9), with I. asiatica, I. ezoin (Asahina, 1952) 
and I. pumilio as the most closely related species. Interestingly, two individuals identified as Ischnura sp., whose sequences were downloaded from GenBank (see Table 1 and Figure 9), clustered together with the specimens from Lijiang sequenced by us, indicating that they are indeed the same species. The author of these sequences, Dr. Ryo Futahashi has confirmed us that these specimens were collected in Xishan District, Kunming, also in the province of Yunnan, ca. $500 \mathrm{~km}$ far from Lijiang (R. Futahashi, personal communication, 2 June 2021).
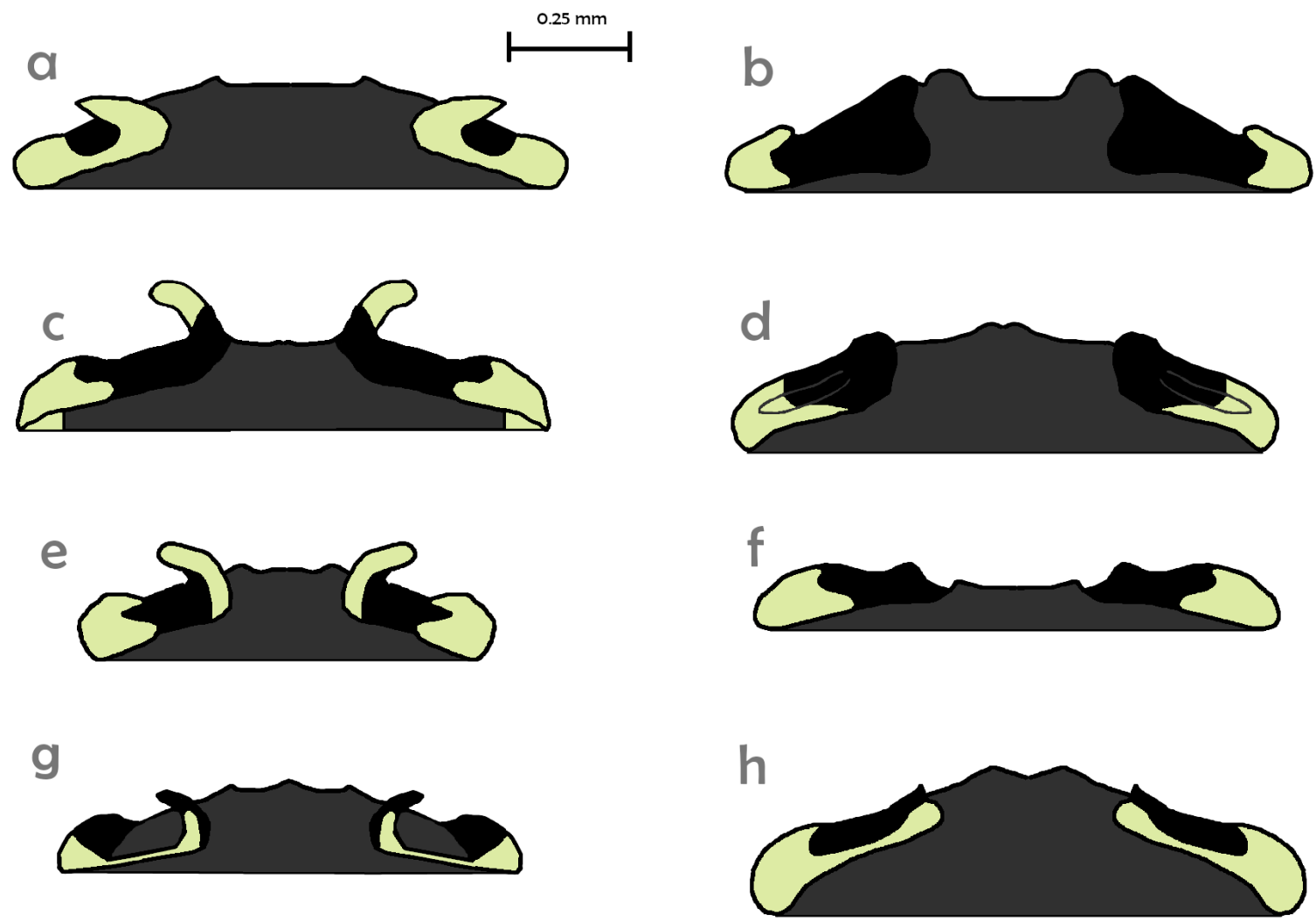

FIGURE 8. Scheme of the mesostigmal plates in portero-dorsal view of Ischnura praematura ( $\delta \mathbf{a}$; $q$ b), I. aurora from China

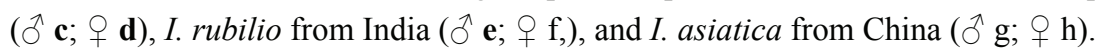

Genetic distances were congruent with the obtained phylogenetic results and generally high between the species included in the analysis (Table 2). For the mtDNA, genetic distances between I. praematura and the rest of the Ischnura species ranged between $11.23 \%$ for the I. praematura/I. asiatica pair and $16.67 \%$ for I. praematura/I. ramburii (Selys, 1850). For the nDNA genetic distances were lower than for mtDNA. Genetic distances for the ITS marker between I. praematura and other Ischnura species included in the study ranged from $2.58 \%$ for the $I$. praematura/I. ezoin pair to $8.58 \%$ for I. praematura/I. senegalensis (see Table 2).

Despite their apparent morphological similarities, I. aurora and I. praematura fall within two distinct genetic clades. Even if we were not able to include I. rubilio in the genetic analyses carried out for the present study, given the high morphological similarity of this species with I. aurora, we would expect I. rubilio to be more genetically similar to I. aurora than to I. praematura.

Ecological and behavioural observations. The Lijiang I. praematura population showed high density and a balanced sex ratio (167 mature males and 170 mature females captured in 10 minutes by one person). Only three immature males and four immature females were observed during mark and recapture. Mature males (Figure 10a) were observed in tandem with both mature and teneral females (see a tandem with teneral female in Figure 10c). While in tandem, males tried to pull females from the substrate with their legs. Mature females in tandem rejected the male mating attempts shaking all body parts and keeping their abdomen in a straight position without touching the male's secondary genitalia (see Robertson \& Tennessen 1984). Despite the high density of the population, we did not record any mating involving mature females, but we detected two matings involving mature males and teneral females (Figure 10d). To our knowledge, mating by teneral females has only been reported in I. aurora from Oceanian populations (Rowe 1978, 2010), while this behaviour is not present in Indian I. aurora (Srivastava \& Babu 1984). 


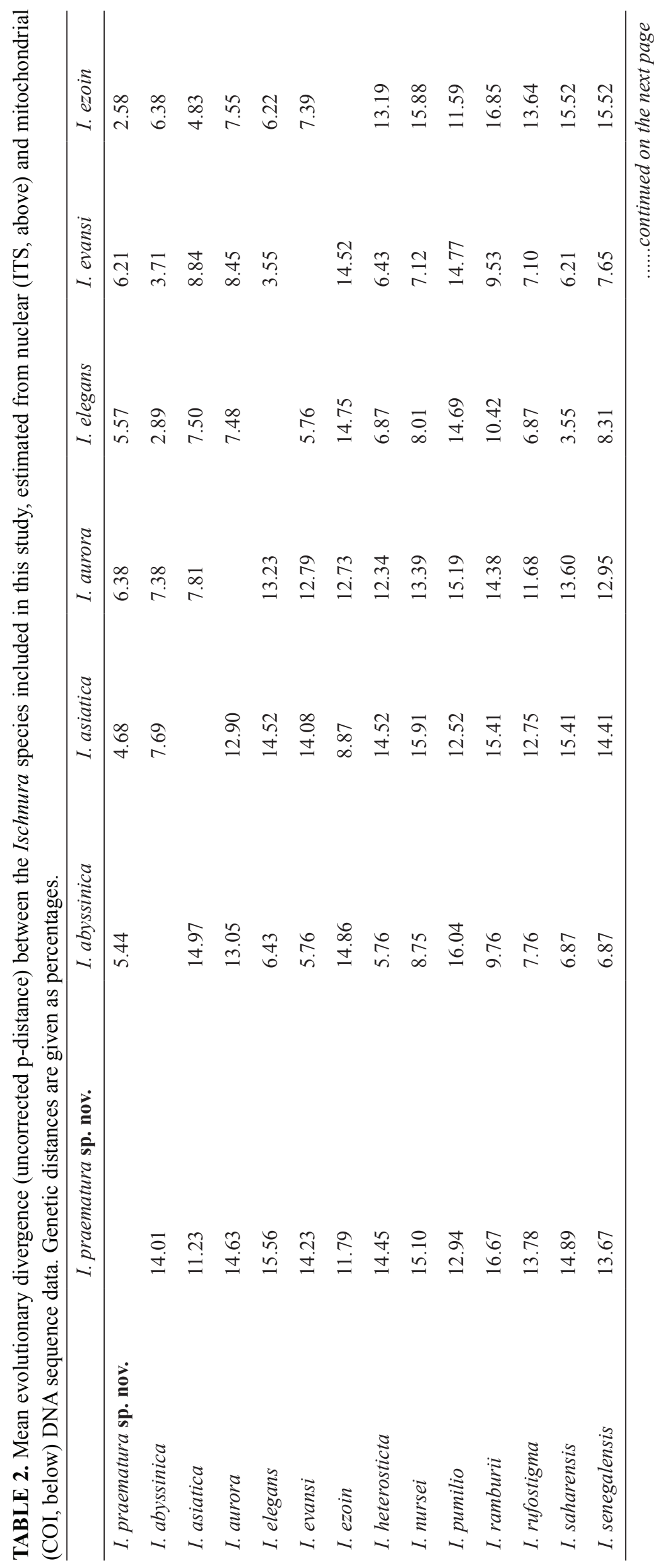




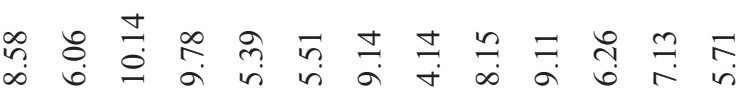

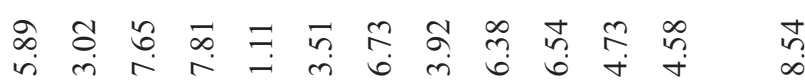

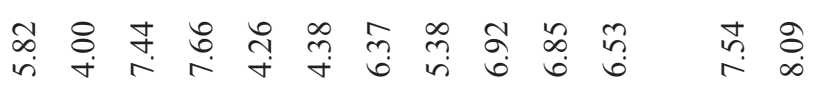

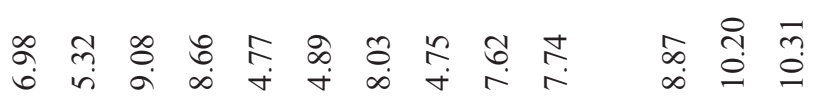

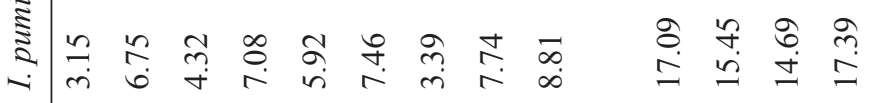

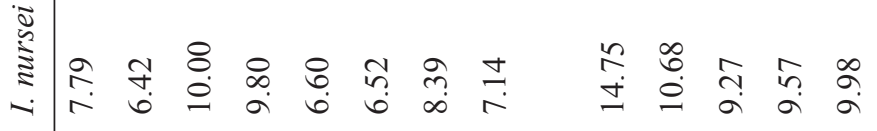

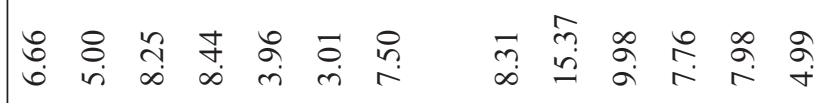

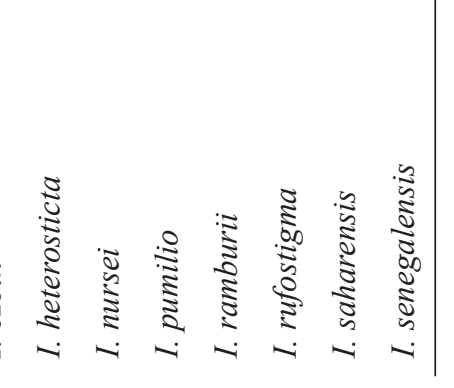




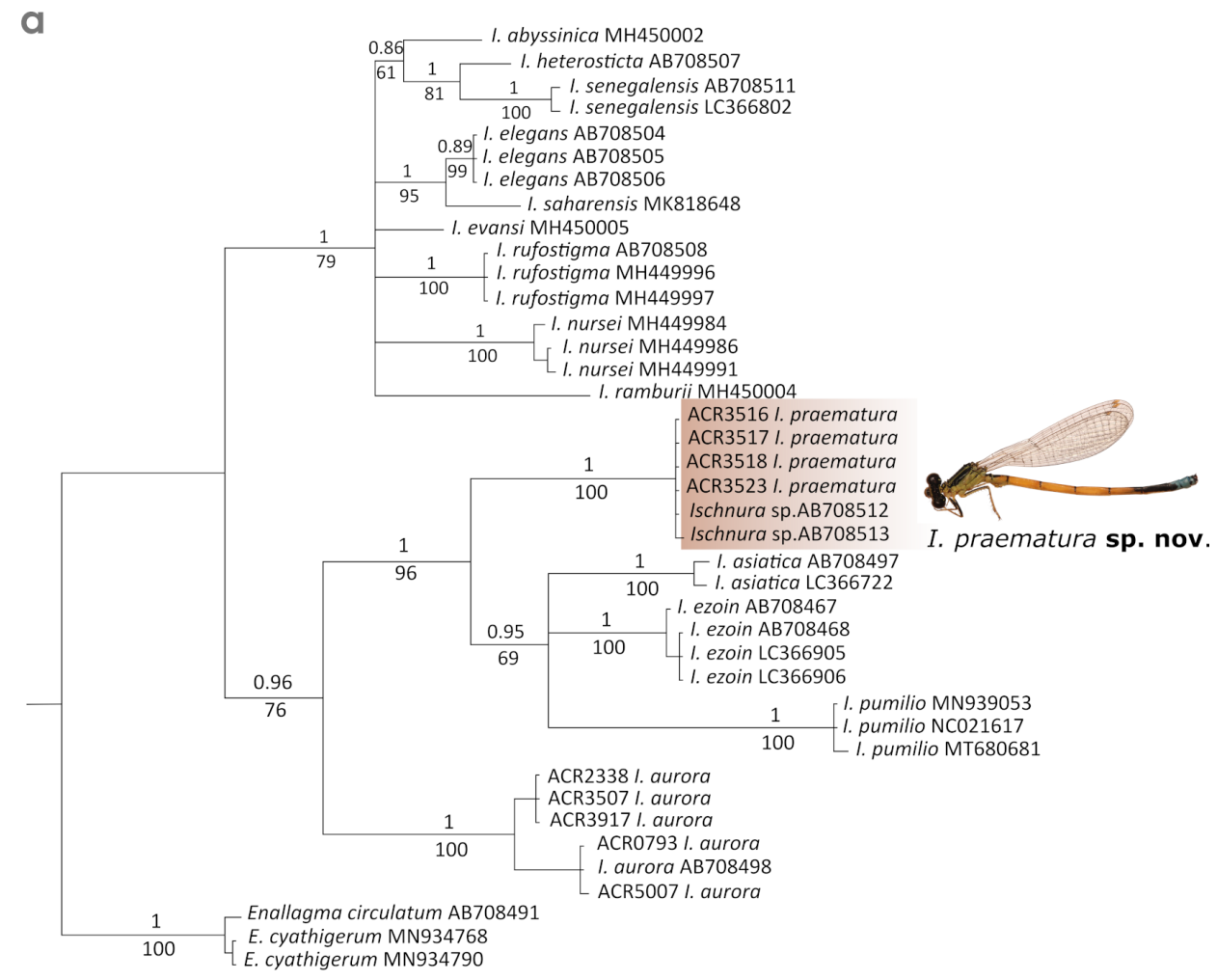

b

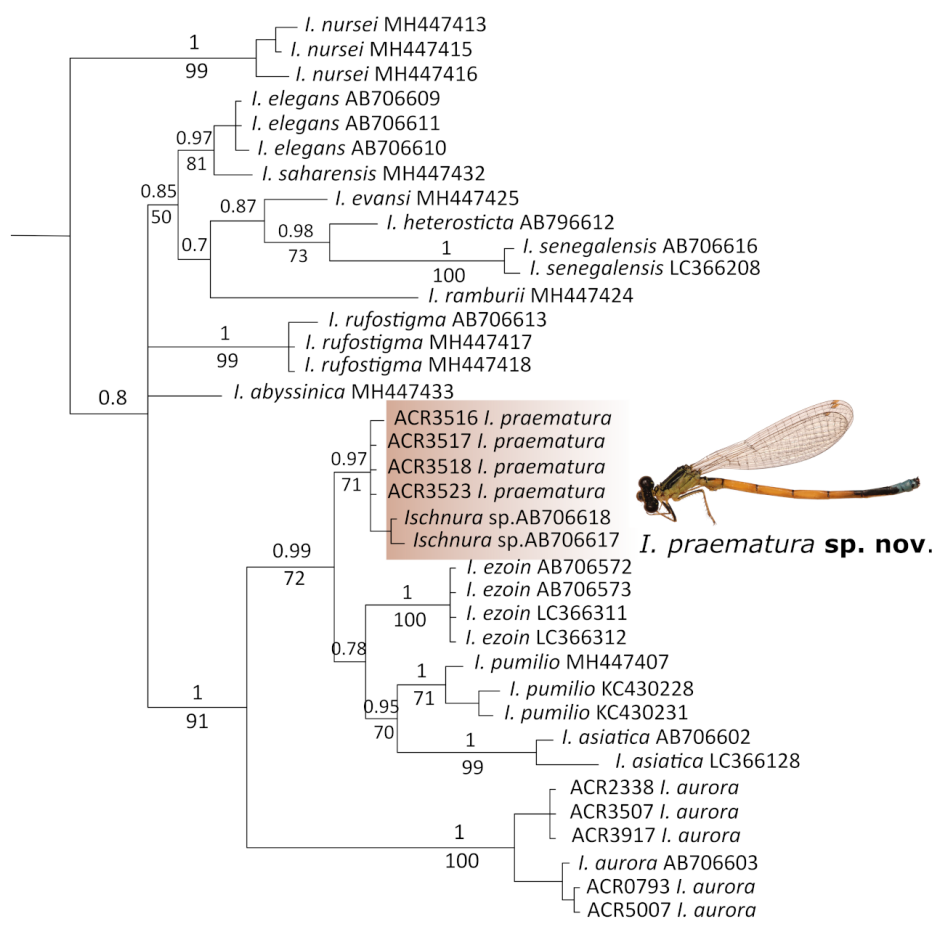

FIGURE 9. Trees representing the phylogenetic relationships between the Ischnura species included in this study using (a) mitochondrial DNA (COI; 451 bp) and (b) nuclear DNA (ITS; 610 bp) sequence data. Ischnura praematura clade appears highlighted in pink. Numbers above and below branches represent Bayesian Inference posterior probability values and Maximum Likelihood bootstrap values, respectively. Only bootstrap values equal or greater than $50 \%$ are shown. Note that in (b) only the ingroup (i.e. Ischnura clade) is depicted. For those species whose sequences were downloaded from GenBank to be included in the genetic analyses, accession numbers are indicated after each species name. In (b), outgroup GenBank accession numbers are as follows: MN963489 and MN963513 for Enallagma cyathigerum, and AB706596 for E. circulatum. 


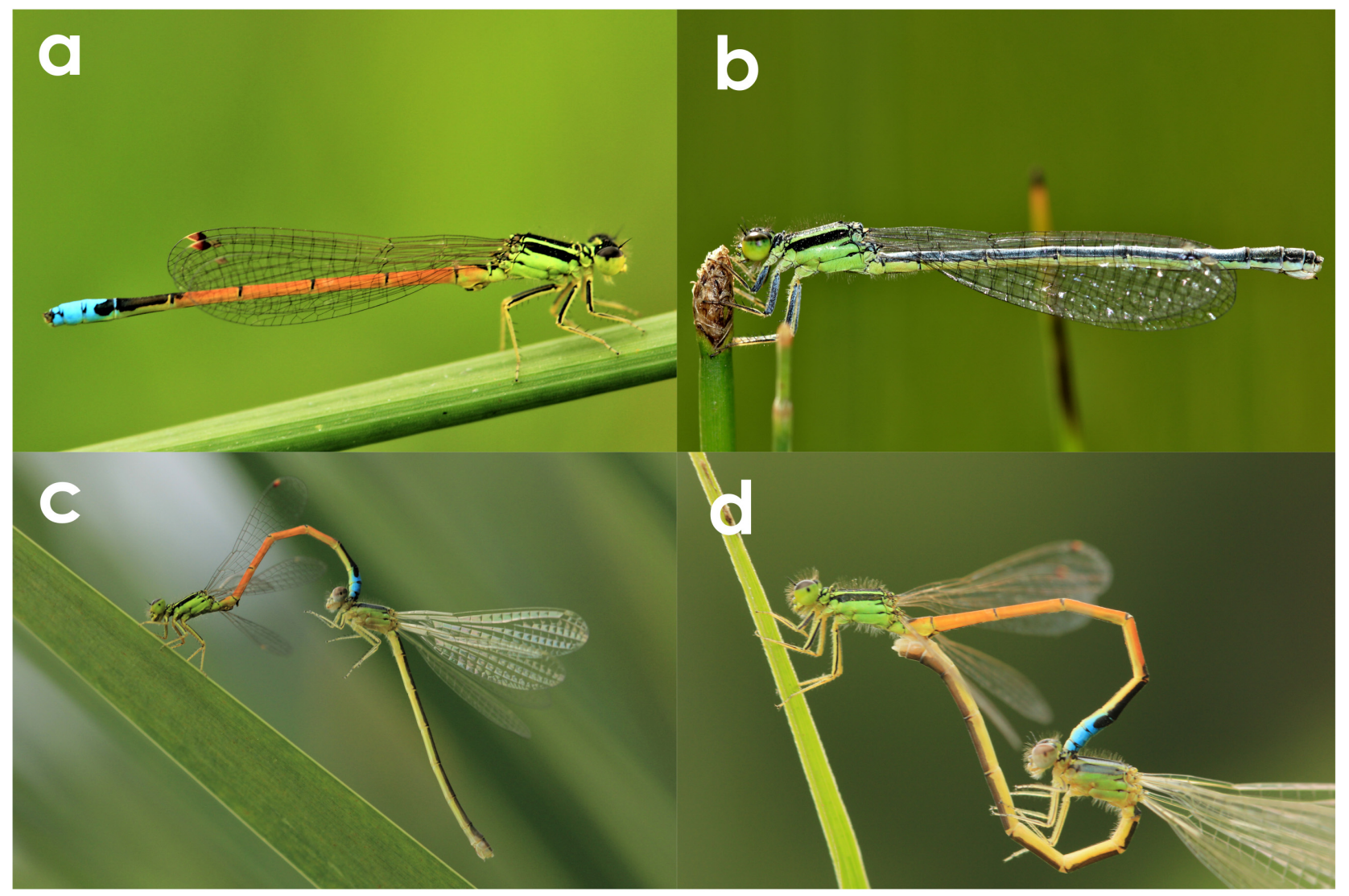

FIGURE 10. Ischnura praematura mature male (a) and female (b) as seen in the field, nearby Lijiang city. Note the pruinescence in the abdomen and legs of the mature female and the wing hardness in comparison with the females of the following pictures. Tandem (c) and mating (d) observed in the field between a mature male and a teneral female. All photos by I. SanmartínVillar.

\section{Acknowledgements}

We thank M. Bedjanič, R. Babu, K. A. Subramanian, and H. Dumont for sharing their Ischnura rubilio material with us and Ryo Futahashi for sharing information about the location where he collected the specimens of I. praematura. We thank Milen Marinov and two anonymous reviewers for improving this paper with their valuable comments. We thank Professor Quinghua Cai, director of the State Key Laboratory of Freshwater Ecology and Biotechnology of the Institute of Hydrobiology (Wuhan) and his team, for their help to ISV during his stay in China. ISV was supported by two grants of the Spanish Ministry with competences in science (BES-2012-052005 and EEBB-I-1509382). This work was funded by grants CGL2014-53140-P and PGC2018-096656-B-I00 to ACR from MCIN/ AEI/10.13039/501100011033 and from "ERDF A way of making Europe", by the "European Union".

\section{References}

Cordero-Rivera, A. (1987) Estructura de población en Ischnura (Zygop. Coenagrionidae). Boletín de la Asociación española de Entomología, 11, 269-286.

Cordero-Rivera, A. (2017) Behavioral diversity (ethodiversity): a neglected level in the study of biodiversity. Frontiers in Ecology and Evolution, 5, 1-7. https://doi.org/10.3389/fevo.2017.00007

Cordero-Rivera, A. \& Córdoba-Aguilar, A. (2010) Selective forces propelling genitalic evolution in Odonata. In: CórdobaAguilar, A. \& Leonard, J. (Eds), The evolution of primary sexual characters in animals. Oxford University Press, Oxford, pp. 332-352. 
Debecker, S., Sanmartín-Villar, I., de Guinea-Luengo, M., Cordero-Rivera, A., Stoks, R. (2016) Integrating the pace-of-life syndrome across species, sexes and individuals: covariation of life history and personality under pesticide exposure. Journal of Animal Ecology, 85, 1-13. https://doi.org/10.1111/1365-2656.12499

Dijkstra, K.-D.B. \& Lewington, R. (2006) Field guide to the dragonflies of Britain and Europe. Bloomsbury, 318 pp.

Futahashi, R., Okude, G., Sugimura, M. \& Ugai, S. (2018) Interspecific hybrids in Japanese Odonata. Tombo, 60, 1-49.

Garrison, R.W., von Ellenrieder, N. \& Louton, J.A. (2010) Damselfly genera of the New World. Johns Hopkins University Press, Baltimore, $490 \mathrm{pp}$.

Huelsenbeck, J.P. \& Ronquist, F. (2001) MRBAYES: Bayesian inference of phylogenetic trees. Bioinformatics, 17, 754-755. https://doi.org/10.1093/bioinformatics/17.8.754

Katoh, K., Misawa, K., Kuma, K.I. \& Miyata, T. (2002) MAFFT: A novel method for rapid multiple sequence alignment based on fast Fourier transform. Nucleic Acids Research, 30, 3059-3066. https://doi.org/10.1093/nar/gkf436

Katoh, K. \& Standley, D.M. (2013) MAFFT multiple sequence alignment software version 7: Improvements in performance and usability. Molecular Biology and Evolution, 30, 772-780. https://doi.org/10.1093/molbev/mst010

Kumar, S., Stecher, G., Li, M., Knyaz, C. \& Tamura, K. (2018) MEGA X: Molecular evolutionary genetics analysis across computing platforms. Molecular Biology and Evolution, 35, 1547-1549. https://doi.org/10.1093/molbev/msy096

Lorenzo-Carballa, M.O., Hadrys, H., Cordero-Rivera, A. \& Andrés, J.A. (2012) Population genetic structure of sexual and parthenogenetic damselflies inferred from mitochondrial and nuclear markers. Heredity, 108, 386-95. https://doi.org/10.1038/hdy.2011.84

Miller, M.N. \& Fincke, O.M. (1999) Cues for mate recognition and the effect of prior experience on mater recognition in Enallagma damselflies. Journal of Insect Behavior, 12, 801-814.

Robertson, H.M. \& Tennessen, K.J. (1984) Precopulatory genital contact in some Zygoptera. Odonatologica, 13, 591-595.

Ronquist, F. \& Huelsenbeck, J.P. (2003) MrBayes 3: Bayesian phylogenetic inference under mixed models. Bioinformatics, 19, $1572-1574$. https://doi.org/10.1093/bioinformatics/btg180

Rowe, R.J. (1978) Ischnura aurora (Brauer), a dragonfly with unusual mating behaviour (Zygoptera: Coenagrionidae). Odonatologica, 7, 375-383.

Rowe, R.J. (2010) Ischnura aurora (Brauer 1865) (Zygoptera: Coenagrionidae), an Australo-Pacific species. New Zealand Journal of Zoology, 37, 189-192. https://doi.org/10.1080/03014223.2010.488789

Sánchez-Guillén, R.A., Ceccarelli, S., Villalobos, F., Neupane, S., Rivas-Torres, A., Sanmartín-Villar, I., Wellenreuther, M., Bybee, S., Velasquez-Vélez, M.I., Realpe, E., Chávez-Ríos, J.R., Dumont, H.J. \& Cordero-Rivera, A. (2020) The evolutionary history of colour polymorphism in Ischnura damselflies. Odonatologica, 49, 333-370. https://doi.org/10.5281/zenodo.4268559

Sánchez-Guillén, R.A., Van Gossum, H. \& Cordero-Rivera, A. (2005) Hybridization and the inheritance of female colour polymorphism in two ischnurid damselflies (Odonata: Coenagrionidae). Biological Journal of the Linnean Society, 85, 471-481. https://doi.org/10.1111/j.1095-8312.2005.00506.x

Sanmartín-Villar, I. \& Cordero-Rivera, A. (2016) The inheritance of female colour polymorphism in Ischnura genei (Zygoptera: Coenagrionidae), with observations on melanism under laboratory conditions. PeerJ, 4, 1-19. https://doi.org/10.7717/peerj.2380

Sanmartín-Villar, I., Zhang, H. \& Cordero-Rivera, A. (2016) Colour polymorphism and ontogenetic colour changes in Ischnura rufostigma (Odonata: Coenagrionidae). Odonatologica, 45, 77-86. https://doi.org/10.5281/zenodo.50850

Srivastava, B.K. \& Babu, B.S. (1984) Some observations on oviposition of Ischnura aurora (Brauer) in Indian biotope (Zygoptera: Coenagrionidae). Fraseria, 7, 24.

Stamatakis, A. (2014) RAxML version 8: A tool for phylogenetic analysis and post-analysis of large phylogenies. Bioinformatics, $30,1312-1313$. https://doi.org/10.1093/bioinformatics/btu033

Zhang, H.M. (2019) Dragonflies and damselflies of China. Chongqing University Press, Chongqing, 1460 pp. 